\title{
Species differences in responses to captivity: stress, welfare and the comparative method
}

\author{
Georgia J. Mason \\ Animal \& Poultry Science Department, University of Guelph, Guelph, Ontario N1G 2W1, Canada
}

\begin{abstract}
Approximately 26 billion animals, spanning over 10000 species, are kept on farms and in zoos, conservation breeding centers, research laboratories and households. Captive animals are often healthier, longer-lived and more fecund than free-living conspecifics, but for some species the opposite is true. Captivity is a very long way from the ideal 'common garden' often assumed by evolutionary and ecological researchers using data for captive animals. The use of comparative methods to investigate the fundamental biological causes of these species differences would help to improve husbandry and enclosure design, and might even reveal relationships between susceptibilities to poor captive welfare and susceptibilities to anthropogenic threat in the wild. Studies of these species differences could also inspire and facilitate 'evo-mecho' research into the functions of behavioral control mechanisms.
\end{abstract}

\section{Animal welfare science and the wellbeing of captive wild animals}

The poor wellbeing experienced by some animals in zoos, laboratories and other captive situations is both a problem that needs to be solved and an opportunity to address fundamental questions about behavioral evolution. Important for both these topics is the enormous variation between species in how they react to captivity, as illustrated in the first section of this review. This variation can be used for hypothesis testing by means of comparative methods, which involves statistical comparison of multiple species with differing phenotypes. I summarize four studies that have used comparative methods to investigate causes of poor welfare in zoos and show the enormous potential of this approach for future research. For example, new hypotheses to test are suggested by recent insights from conservation biology into links between invasiveness and the ability to thrive in human proximity, the special traits of 'weed species' and 'urban invaders' seeming likely to help them flourish in captivity. One clear conclusion of this review is therefore that ecological and evolutionary biology has much to offer animal welfare research. However, as the final section argues, the benefits are not just one-way. Animal welfare data highlight the dangers of uncritical use of captive animals to test ecological or evolutionary hypotheses by demonstrating that captivity is not always the benign backdrop that is generally assumed

Corresponding author: Mason, G.J. (gmason@uoguelph.ca) in such work. Welfare data also raise novel 'evo-mecho' [1] hypotheses to test, because some responses to captivity suggest new insights into the mechanisms that control behavior. To end, I highlight recent advances, especially the increasing availability and quality of data from zoos, that make the application of comparative methods to welfare issues timely.

As a scientific discipline, animal welfare science needs some introduction. This field evaluates the wellbeing of animals controlled by humans [2-5], principally the vast numbers kept confined (e.g. the 25000000000 farm animals, http://faostat.fao.org/site/573/default.aspx\#ancor). Its research topics include the welfare impacts of enclosure sizes and housing conditions that prevent species-typical natural behaviors. It informs and shapes legislation and guidelines on humane care, which comprise ethically driven policies that assume that animals, or at least homeotherms, are sentient and able to suffer. Welfare scientists therefore often make explicit inferences about animal feelings (e.g. pain, fear, frustration), states that cannot be measured directly but are inferred using a toolbox of indices. These indices will be familiar to biologists interested in stress physiology, responses to predators and constraints on reproduction or immunity [6-10]. They include the avoidance of potential threat (e.g. escape responses), associated acute stress responses (e.g. catecholamine and corticosteroid release) and their functional consequences (e.g. increased heart and ventilation rates), and long-term responses such as adrenal enlargement, compromised growth, reproductive suppression and immunosuppression. Box 1 describes an additional index: stereotypic behavior. As discussed below, these indices can reveal much about the welfare of captive wild animals.

\section{Captivity: a haven for some species but more prison-like} for others?

There is wide variation in how animals respond to captivity, and in some cases chronic stress seems to be an influence. Captive wild animals generally receive ample food and water, veterinary care, and protection from predation and conflict. Consequently, they are often healthier, live longer and breed more successfully than conspecifics living free in their natural environments. Many zoos have impressive longevity records, and some captive populations would have exponential growth rates were they not managed to prevent this [11-14]. However, not all captive wild animals flourish in this way, with some surviving and 


\section{Box 1. Stereotypic behavior: a captivity-induced behavioral anomaly with great interspecies variation}

Suboptimal captive environments induce abnormal, repetitive stereotypic behavior by eliciting sustained attempts to perform specific normal activities, and in some cases by disrupting normal brain development leading to general tendencies to show behavioral inflexibility $[22,62,79]$. Species differ greatly in how readily they develop stereotypic behavior, with some species displaying little because they adjust well to captivity and others displaying little because they instead react with profound inactivity (Box 2). Species also differ greatly in what forms they display. Zoo-housed walruses, for example, stereotypically rub their tusks on concrete structures such as pool edges [74,78]. This activity can so damage the tusks, risking infection, that zoos remove them (Figure la). Walruses seem to be the only captive pinniped with an oral stereotypic behavior, probably reflecting their unusual, naturally molluscivorous diet: the tusk rubbing resembles actions used when

(a)

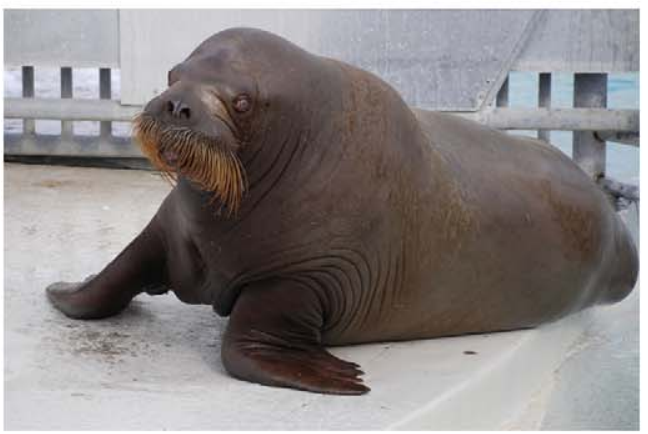

foraging on mollusc beds in the wild. Another stereotypic behavior that possibly derives from natural foraging movements is the feather and skin plucking common in some birds, including caged parrots (Figure lb) $[79,80]$. Cockatoos, as shown here, are very prone to self-plucking, whereas certain other parrot species are far less prone (Table 1). This interspecies variability could potentially be used in the future to pinpoint the fundamental origins of this behavior (see the text). Species differences similarly occur in the pacing and swaying typical of caged carnivores (Figure Ic); within this taxon, those species in which it is most time-consuming tend to be naturally wide-ranging (see the text) $[22,32]$. Stereotypic behavior patterns like these are widely used in welfare research, but not to date in evolutionary or ecological work. However, they might provide 'evo mecho' insights into the evolution of different types of behavioral control mechanisms (see the text). (b)

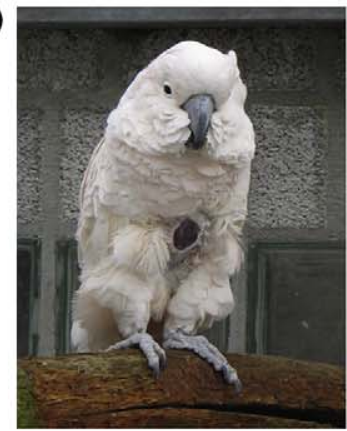

(c)

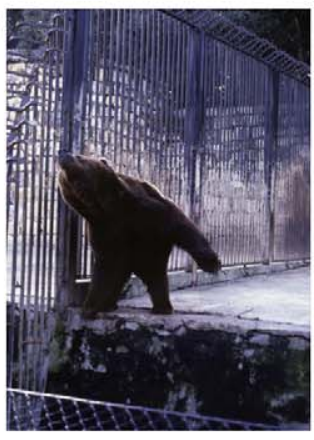

TRENDS in Ecology \& Evolution

Figure I. Stereotypic behaviour and its consequences. (a) A tuskless captive walrus (image from iStockPhoto). (b) Self-harm in a cockatoo (image supplied by the World Parrot Trust). (c) A stereotypic captive bear (image supplied by the Born Free Foundation).

breeding far less well than might be expected. Furthermore, the evidence of compromised welfare often suggests that physiological or psychological needs are not being met.

Forest duikers (Cephalophus spp.) in zoos, for instance, are 'highly susceptible to stress' [15], vulnerable to opportunistic infections such as jaw abscesses [15], and commonly have infant mortality rates of $30-40 \%$ [16], which is higher than typical for ungulates in good conditions [12]. Giraffes (Giraffa cameleopardalis) have a shorter lifespan in zoos than when protected in the wild [17], an effect seemingly linked to poor nutritional status and low energy intake, suggesting inadequacies in zoo diets [17]. Furthermore, many captive giraffes (at least $75 \%$ of the North American population [18]) show oral stereotypic behaviors such as wall licking. African elephants (Loxodonta africana) also have a shorter lifespan in zoos than when protected in the wild, whereas zoo-born Asian elephants (Elephas maximus) have a shorter life than conspecifics born in Burmese timber camps [19]. In zoos, both species also have reproductive problems such as high infant mortality and abnormal estrous cycling [14,19,20] and are not self-sustaining [20]. Furthermore, many zoo elephants (at least 50\% [14]) perform stereotypic behavior. Cheetahs (Acinonyx jubatus) in Western zoos are similarly not self-sustaining [21] because of reproductive problems, including high infant mortality [22]. Zoo-housed cheetahs also have elevated cortisol outputs, hypertrophied adrenal glands, and enhanced vulnerability to a Helicobacter species that seems to be non-pathogenic in wild cheetahs but causes severe gastritis in zoo animals (http://www.cbsg.org/ cbsg/workshopreports/26/global_cheetah_conservation_ plan_final_report_2002.pdf, [21-23]).

Finally, breeding colonies of Humboldt penguins (Spheniscus humboldti) in UK zoos have approximately half the chick output of free-living, undisturbed wild colonies (see the supporting material online, [24,25]), and in these and other penguin species, aspergillosis, a stressrelated opportunistic fungal infection, is more prevalent in captive than in wild populations [26].

In all these cases, zoo animals fare worse than expected given benchmark data from other protected populations. This is paradoxical given the potential benefits of captivity. It is not the only paradox. A second is that many other species thrive in similar conditions. Table 1 illustrates this species variation in more detail (with further examples in the next section) and Box 2 discusses the types of data needed to make valid conclusions about the relative welfare of different species. Overall, it is evident that even close taxonomic relatives can differ enormously in captive wellbeing: some species have arguably acceptable or even good welfare, whereas their congeners display evidence of stress in similar conditions. This in turn suggests that, compared with their more easygoing relatives, the latter species have requirements that are either particularly difficult to accommodate in captivity or are simply not yet understood.

These puzzling contrasts could hold the key to understanding such welfare problems. Traditional approaches for identifying causes of poor welfare include epidemiological investigations that exploit existing variation between facilities, and experimental manipulations of management 
Table 1. Closely related species with unexplained variation in captive welfare

\begin{tabular}{|c|c|c|c|c|}
\hline Taxon & Species with relatively poor captive welfare & Refs & Species with relatively good captive welfare & Refs \\
\hline Prosimians & $\begin{array}{l}\text { Gentle lemur (Hapalemur spp.) } \\
\text { - Reportedly timid, with many abnormal behaviors; } \\
\text { poor reproduction in captivity } \\
\text { Black lemur (Eulemur macaco) } \\
\text { - Infant mortality rate in zoos } 27 \% \text { in } 1984 \\
\text { - Prevalence of stereotypic behavior } 55 \%\end{array}$ & $\begin{array}{l}{[66]} \\
{[67]}\end{array}$ & $\begin{array}{l}\text { Ring-tailed lemur (Lemur catta) } \\
\text { - Reportedly minimal behavioral and veterinary } \\
\text { problems; excellent breeding success } \\
\text { - Infant mortality rate in zoos } 21 \% \text {; lowest of five } \\
\text { lemurs surveyed in } 1984 \text {, and more recently } \\
\text { estimated at just } 10-15 \% \\
\text { - Prevalence of stereotypic behavior } 6 \%\end{array}$ & $\begin{array}{l}{[65]} \\
{[66,68]^{\mathrm{a}}}\end{array}$ \\
\hline Cetaceans & $\begin{array}{l}\text { Orca (Orcinus orca) } \\
\text { - Annual mortality rates of 4-6\% in captivity, compared } \\
\text { with } 2-3 \% \text { in the wild, a significant difference } \\
\text { resulting in an expected lifespan of half to two-thirds } \\
\text { of that occurring naturally [http://dukespace.lib. } \\
\text { duke.edu/dspace/handle/10161/230] } \\
\text { - Although 'successfully kept and bred in captivity', the } \\
\text { IUCN describes this success as 'Limited' } \\
\text { - 'Can be aggressive, several attacks on trainers } \\
\text { occurred' } \\
\text { Fraser's dolphin (Lagenodelphis hosei) } \\
\text {-'Shy, nervous, and refuse[s] to eat; fragile in captivity; } \\
\text { unsuccessfully kept so far; probably unsuitable for } \\
\text { captivity' } \\
\text { Dall's porpoise (Phocoenoides dalli) } \\
\text { - 'Unsuccessful in captivity, throwing itself against } \\
\text { walls and bottom; refuses to feed, nervous, irritable, } \\
\text { subject to infection and skin slough... probably } \\
\text { unsuitable for captivity' }\end{array}$ & $\begin{array}{l}{[71]} \\
{[71]}\end{array}$ & $\begin{array}{l}\text { Bottle-nose dolphin (Tursiops truncatus) } \\
\text { - Annual mortality rates not significantly different } \\
\text { from those in the wild, as long as recent data are } \\
\text { used [http://dukespace.lib.duke.edu/dspace/ } \\
\text { handle/10161/230]. } \\
\text { - Reproductive rates can be faster than in the wild } \\
\text { - 'the most common species of cetacean kept in } \\
\text { captivity; highly adaptable... successfully kept } \\
\text { and bred in captivity' } \\
\text { Finless porpoise (Neophocaena phocaenoides) } \\
\text { - 'Playful in captivity... successfully kept and bred' }\end{array}$ & $\begin{array}{l}\text { [71] } \\
\text { [71] }\end{array}$ \\
\hline Pinnipeds & $\begin{array}{l}\text { Walrus (Odobenus rosmarus) } \\
\text { - Shorter lifespan than in the wild } \\
\text { - Reports and census data suggest poor reproduction } \\
\text { in zoos } \\
\text { - Intense stereotypic rooting of concrete pool edges, } \\
\text { causing tusk wear (see Figure I in Box 1) }\end{array}$ & $\begin{array}{l}{[76,77]} \\
{[74,75,} \\
77,78]\end{array}$ & $\begin{array}{l}\text { Gray seal (Halicheorus gypus) } \\
\text { - Similar survivorship in captivity as in the wild } \\
\text { http://dukespace.lib.duke.edu/dspace/handle/ } \\
\text { 10161/230]. } \\
\text { - Census data suggest few breeding problems in } \\
\text { zoos }\end{array}$ & {$[79,80,83]$} \\
\hline Psittacines & $\begin{array}{l}\text { Cockatoos (Cacatua Psittacus erithacus spp.), African } \\
\text { grey parrots and macaws (Ara spp.) } \\
\text { - Feather plucking (Fig. 1) is common } \\
\text { - Captive breeding of macaws varies with species, } \\
\text { some breed readily but others very poorly }\end{array}$ & $\begin{array}{l}{[79,80]} \\
{[51,81]}\end{array}$ & $\begin{array}{l}\text { Lorikeets and lories (Lorius spp. and related genera } \\
\text { in the Loriinae) and budgerigars (Melopsittacus } \\
\text { undulatus) } \\
\text { - Feather-plucking is very uncommon } \\
\text { - Also breed readily in captivity }\end{array}$ & $\begin{array}{l}{[79,80,83]} \\
{[81,82]}\end{array}$ \\
\hline
\end{tabular}

${ }^{a}$ See the supplementary material online.

or husbandry regimes [2-5]. However, interspecies variation in welfare can be used for a complementary, and potentially extremely valuable, third approach: comparative methods.

\section{Species variation in responses to captivity as an emerging way to solve welfare problems}

Comparative methods involve hypothesis testing using data from multiple species with statistical testing of, and if necessary control for, phylogenetic non-independence (similarities between related taxa because of shared traits from a common ancestor) [27-29]. Widely used in evolutionary and ecological research and successfully applied to identify conservation risk and protective factors $[28,29]$, these methods can also be used to investigate welfare problems.

Two early studies involved multispecies behavioral data collected in zoos. Neither tested for phylogenetic non-independence, so their findings are intriguing hints rather than conclusive. However, they provided the first demonstrations that species differences in welfare are nonrandom. Chamove and colleagues investigated how visi- tors affect zoo primates [30]. Across 12 species, they found that human proximity caused increases in activity. They hypothesized that smaller-bodied species were most affected and that differences existed between arboreal and terrestrial primates. Their cross-species comparisons significantly supported the former hypothesis (see the supplementary material online). This suggests that relatively small primates are particularly threatened by the presence of humans. Mettke measured parrot responses to novel objects placed in their aviaries [31]. Six species scored as being prone to feather plucking (see Figure I in Box 1) performed far more protracted exploration than three scored as not prone (see the supplementary material online). This suggests that frustrated exploration might underlie feather plucking, so that the pre-emptive provision of opportunities to explore might be beneficial for captive investigatory species.

A more recent study by my own laboratory investigated whether carnivore welfare is affected by the degree to which captivity constrains natural activities such as hunting and ranging $[22,32]$. We used data on captive infant mortality and stereotypic pacing or swaying (see Figure I 


\section{Box 2. Comparing captive welfare across species}

Comparison of welfare across species requires certain checks to ensure that any differences truly reflect differential responses to captivity. Species differences in baseline attributes, response style or husbandry might otherwise lead to incorrect inferences about differential welfare.

Species differences in baseline attributes: For some welfare indices, problems are signaled by changes from a norm. When species differ in their norms (as is often the case for longevity, infant mortality, corticosteroid output, etc.) these baselines must not be confused with responses to captivity. To illustrate, the mortality rates of six captive pinniped species differ, with Northern fur seals (Callorhinus ursinus) having the highest [85]. Concluding that Northern fur seals are least suited to captivity would be naïve, however: they could have an intrinsically shorter lifespan, with lower annual survival rates even in optimal free-ranging conditions.

Species differences in response style: Some aversive stimuli provoke divergent reactions. Predation threat, for instance, can elicit flight or freezing $[7,9]$, whereas in captivity, some animals become inactive and apathetic instead of stereotypic [62]; these differences are sometimes termed proactive and reactive responses [86]. Recording just one response while ignoring the alternative could erroneously suggest differences in welfare. To illustrate, when seven rodent species were tested in an illuminated unfamiliar arena, the two caviomorphs responded very differently: chinchillas (Chinchilla

in Box 1) for 31 species, controlling for phylogenetic relatedness using phylogenetically independent contrasts. Being naturally wide-ranging predicted greater stereotypic behavior and captive infant mortality, suggesting that designing enclosures with natural ranging in mind (for instance, providing more space, multiple den sites, or greater day-to-day environmental variability) would improve carnivore welfare, and that targeting such improvements on naturally wide-ranging species might pre-empt the emergence of welfare problems. More recent- laniger) scurried about, defecating extensively, whereas guinea pigs (Cavio porcellus) remained huddled and inactive [87]. Using freezing as the sole index might suggest that guinea pigs found the arena most aversive, but this conclusion would obviously be simplistic given that other indices show that chinchillas also found it stressful.

Solutions to these potential problems are to compare values for captive animals with optimum or benchmark values determined for the same species, and to use more than one index to infer welfare to check that they lead to similar conclusions [14,22].

Species differences in husbandry: Ecological niche or other attributes might encourage systematic patterns in husbandry that induce species differences in captive welfare. Depending on the precise research question, such differences in husbandry would be interesting topics for analysis or could represent potential confounds that require statistical control $[22,33]$.

For example, given limited space, large species might tend to be housed in smaller enclosures for their body size, whereas species from polar or desert environments might be given barren enclosures which mimic these human eyes. Captive species can also vary in population size or tendencies for males and females to be housed together, affecting reproductive opportunities in a manner analogous to 'propagule pressure' (see the text). Species can also differ in 'husbandry effort', with endangered species perhaps attracting more solicitous care and resources [33].

ly still, Müller and colleagues used information on over 45 000 individual deer from the International Species Inventory System (ISIS; Box 4) [33]. Their innovative analyses involved calculating the ratio of mean lifespan in captivity to the maximum ever recorded for each of 20 species, to control for species differences in normal intrinsic life expectancy (Box 2). In females, for whom sample sizes were larger and intraspecific aggression not an issue, these values negatively co-varied with the percentage of browse (leafy material from trees and bushes) in their natural diet,

\section{Box 3. Ethological welfare risk factors: hypotheses for future testing using comparative methods}

Specific natural behaviors that are constrained by captivity have often been suggested as welfare risk factors. They and their testable predictions are summarized below (see the text for additional hypotheses concerning species-typical personality traits and conservation status). Future tests should incorporate controls for phylogenetic non-independence, where needed (see the text); the checks outlined in Box 2; and, ideally, large sample sizes (with species as the unit of replication).

\section{Feather and skin plucking in parrots: alternatives to the exploration} hypothesis (see the text)

Hypothesis I: This behavior is induced by social isolation [79,88].

Prediction: Feather and skin plucking will be most severe or prevalent in the most social species; effects will be stronger in birds kept as pets (often without conspecifics) than in reputable zoos or breeding centers (generally with conspecifics).

Hypothesis II: This behavior is induced by frustration of natural foraging $[79,80]$.

Prediction: Feather and skin plucking will be most severe or prevalent in species with the most naturally time-consuming or manipulative foraging behavior.

Natural foraging behavior and stereotypic pacing in captive carnivores Hypothesis: Stereotypic pacing derives from aspects of natural hunting (e.g. prey search or pursuit) $[22,89]$.

Prediction: Stereotypic pacing will be most time-consuming or prevalent in species that travel long distances in search of prey or show sustained pursuit, after statistically controlling for the effects of species differences in ranging (see the text) $[22,89]$.

\section{Natural foraging and post-feeding oral stereotypic behaviors}

Hypothesis: Post-feeding oral stereotypic behaviors (e.g. those of walruses [Box 1] and ungulates such as the giraffe [18]) derive from localized food searching [90].

Prediction: Post-feeding oral stereotypic behaviors will typify naturally patch-feeding species, in contrast to species with naturally evenly dispersed or highly mobile food items.

Welfare of captive marmosets and tamarins in laboratories and zoos Hypothesis I: Restrictions on ranging compromise callitrichid welfare [90].

Prediction: Naturally wide-ranging callitrichid species will fare poorest in laboratories and zoos.

Hypothesis II: Restrictions on arboreality compromise callitrichid welfare [91].

Prediction: Species that naturally use the highest regions of the forest canopy and/or least often use the forest floor will fare poorest in laboratories and zoos.

Welfare of cetaceans in aquaria

Hypothesis I: Restrictions on diving compromise welfare in cetaceans [71].

Prediction: Shallow water species will fare better in aquaria than deep water species.

Hypothesis II: Restrictions on travelling long distances compromise welfare in cetaceans [71].

Prediction: Coastal, little-ranging species will have poorer welfare in aquaria than open-ocean pelagic species. 
suggesting that being naturally browsing is a risk factor for shortened captive lifespan. These results need to be checked for the potential effects of phylogenetic non-independence, but given the otherwise superb quality of the study and the poor performance of duikers and giraffes (browsers from two quite different ruminant families; see the previous section), they strongly suggest that meeting the dietary needs of browsers could improve captive welfare in cervids and that diligent monitoring of natural browsers would be a strategic use of zoo resources.

These four studies show the great potential of comparative methods. Like the more traditional techniques of welfare research, they can successfully test hypotheses about causes of poor welfare and can thus help to improve husbandry in targeted, evidence-based ways. However, they can also tackle hypotheses that would otherwise be near impossible to test (e.g. that prevention of hunting frustrates carnivores) and generate predictive rules of thumb for anticipating which as-yet-unstudied species are inherently likely to react well or adversely to captive conditions.

Comparative methods are thus ideal for testing the many other suggested explanations for species differences in welfare, as well as untested hypotheses about the biological roots of welfare problems that abound in the ethological and veterinary literature (Box 3). As discussed below, they could also be used to test new hypotheses generated by recent findings on the traits that help animals to cope with rapid anthropogenic environmental change in the wild.

\section{'Weed species', 'urban invaders' and the potential to flourish in captivity}

Potential threats, such as habitat destruction and human disturbance, and potential opportunities, such as accidental or deliberate release into new environments, arguably share similarities with being placed in captivity. To be successful under these conditions, animals must modify their behavior appropriately (change what and how they eat, how they nest or den, and so on), cope with the close proximity of humans, and not be overstressed by novelty.

\section{Invasive 'weed species' thrive in human proximity}

Laboratory animal texts on rats (Rattus norvegicus), mice (Mus musculus) and rhesus monkeys (Macaca mulatta) often suggest that species that thrive in captivity also tend to be invasive and/or tolerant of urbanization. But do 'weed species' truly succeed everywhere, whether free or captive? Jeschke and Strayer [34] provided the first support for this idea using clever comparative analyses that controlled for the likelihood that both captive and commensal species are simply most often transported to new locations. They investigated why 139 of the 2362 vertebrate species native to either North America or Europe have been moved between these two continents, and why some of these introductions then proved invasive. For 128 of these species, data on the number of countries (in Europe) and states or provinces (North America) where introductions occurred were used to estimate propagule pressure, the number of opportunities a non-native species has to establish itself. Domesticates and other species raised in captivity as pets or for food or sport were classed as human affiliates, as were species that flourish in human settlements (e.g. $R$. norvegicus and the house sparrow, Passer domesticus). Unsurprisingly, human affiliates were more likely to be introduced outside their native range and with higher propagule pressure. However, this was not their only correlate. Once introduced, they were more likely to become established and spread, an effect that was observed even when propagule pressure was statistically controlled for. Thus, traits that help animals to thrive in close proximity to humans do predict invasiveness in the wild. This suggests a new hypothesis for formal testing: invasive species are predisposed to good captive welfare. It also raises questions about what traits confer this type of success.

\section{Do traits conferring resilience to anthropogenic} disturbance in the wild predict good captive welfare? Boldness, behavioral flexibility and being non-migratory have emerged as three key characteristics predicting invasiveness and tolerance of rapid, anthropogenic environmental change in the wild. Intriguingly, a recent paper on the evolution of domestication concludes that timidity, a wide-ranging lifestyle and dietary or habitat specialism are similarly unfavorable for successful domestication [35]. The question thus arises as to whether these traits also predict poor wellbeing in captive wild species.

\section{Boldness}

Bold species show little fear when faced with familiar threats such as predator cues $[9,10]$. This confers resilience to disturbance in the wild because crucial behaviors such as foraging are little interrupted by flight or freezing, and growth and reproduction are not compromised by endocrine stress responses $[8,9,36]$. For example, ecotourism studies have shown that Gentoo (Pygoscelis papua) and Magellanic (Spheniscus megellanicus) penguins, which show little fear of humans, exhibit minimal reproductive suppression at popular ecotourist sites. In contrast, fearful species such as Humboldt and yellow-eyed penguins (Megadyptes antipodes) exhibit impaired breeding [25,37-39]. New comparative research has tested such associations statistically using large, multi-species databases. Avian species that are particularly scared of humans, as assessed by flight distance when approached, have displayed the greatest recent population declines in Europe [40]. These fearful species are also least likely to colonize towns and cities [41].

For captive animals, the trait of boldness versus fearfulness was suggested decades ago as an explanation for why zoo life is stressful for some wild species but not others [42]. However, this increasingly plausible idea remains untested. Captive birds would make ideal subjects for exploring this further, given the new wealth of comparative data on their fear of humans in the wild [36-41].

\section{Resident versus migratory lifestyle}

Being resident or little-ranging rather than migratory also tends to be beneficial in terms of invasion success $[29,43,44]$. For example, resident parrot species are more likely than migratory species to successfully establish 
themselves in new locations [44]. In captivity, being wideranging predicts poorer welfare in carnivores, as already discussed [22,32], and some captive migratory birds also show intense seasonal migratory restlessness and associated physiological stress responses [45]. However, it remains unknown whether being migratory is a consistent risk factor for poor captive welfare.

\section{Behavioral flexibility}

Behavioral flexibility, the ability to cope with new stimuli or resources $[10,29]$, is the third behavioral trait to consistently promote tolerance of rapid, anthropogenic environmental change in the wild. This involves being exploratory rather than avoiding novelty and being able to modify foraging and other behaviors to exploit new opportunities $[10,46]$. Thus, ecological generalists that use a range of habitats and/or food types are consistently more invasive and likely to establish after introductions to new environments $[29,34,47,48]$. Bird species that readily develop new foraging modes, as quantified by recording innovation rates, are likewise most likely to thrive in new environments (as are those with the correlated trait of relatively large brains [46], an effect also evident in mammals [48]).

In captivity, behavioral inflexibility could well confer poor ability to habituate to human proximity or to suppress natural activities that captivity renders impossible or redundant. In addition, it could impede adjustment to new social systems, types of shelter or foraging modes imposed by captive husbandry. In contrast, being highly motivated to explore and innovate might be frustrating in monotonous enclosures, a possibility already suggested by Mettke's work on parrots [31]. This potentially paradoxical impact of behavioral inflexibility versus flexibility has led to contrasting hypotheses that omnivores might adapt particularly well to captivity or, in contrast, might find it frustratingly 'boring' [22]. Future comparative studies might thus reveal that being moderately flexible, without being excessively intelligent or innovative, is optimal for captive welfare.

\section{Conservation status and good captive welfare: are} vulnerable wild species also vulnerable in captivity?

The evidence above suggests that conservation status itself might predict success in captivity, with common species thriving but at-risk species being inherently prone to poor welfare. Consistent with this, two 20-year-old studies revealed that endangered species are numerically underrepresented in zoos [49] and that among captive canids, endangered and vulnerable species have poorer pup survival than common species [50]. Furthermore, a review from that time also argues that endangered bird species are harder to breed in captivity than their non-endangered close relatives [51]. These suggestions now need to be tested more rigorously using appropriate controls for phylogenetic nonindependence, for intrinsic species differences in, for example, reproductive rate, and for the greater husbandry effort that is probably devoted to more endangered species (Box 2).

\section{Captive animal welfare is important for ecology and evolutionary researchers}

Ecology and evolutionary biology clearly have more to offer animal welfare science than just new methodologies. In addition they offer new hypotheses to test and sometimes even the data to test them. However, animal welfare science has much to offer in return. The two main reciprocal benefits are the promotion of more valid, sophisticated use of captive animal data in fundamental research and the proposal of new hypotheses about the adaptive design of behavioral control mechanisms.

\section{Using captive animal data in fundamental research: captivity is no common garden}

Just as researchers assessing the impact of captivity must not overlook intrinsic species differences in norms (Box 2), so researchers interested in intrinsic species differences must not overlook differential welfare when using data from captive animals, because species differ so greatly in responses to captivity.

This problem seems to be unrecognized in most studies using captive species to investigate patterns of natural adaptation, even when the variables involved are stresssensitive (e.g. comparative analyses of immune function [52,53], exploration and neophobia [31,54] and lifespan $[55,56])$. Statements such as 'captive records are preferred because maximum potential lifespan is of interest' [56] treat captivity as an optimum common garden that liberates animals from extrinsic constraints. However, the assumption that captivity is evenly benign is clearly naïve. This view ignores species $\times$ environment interactions in captive animals' data that will at best add noise and at worst cause spurious results. Welfare science suggests some potential solutions. One is to use only upper or lower extreme values (depending on the variable) from each captive species to eliminate the most stressed individuals. Other solutions require additional information, such as using only data from animals in very large, naturalistic enclosures and/or from individuals for which other variables suggest good welfare (good reproductive rates compared to benchmark populations, no stereotypic behavior, etc.). Data on such variables from zoos will become increasingly easy to obtain (Box 4; final section).

\section{Using animal responses to captivity to generate and test new 'evo-mecho' hypotheses}

The responses of animals to captivity can be used to generate novel evo-mecho hypotheses in at least three ways: by highlighting the diversity of control mechanisms underlying different behaviors; by showing the degree to which behavior is affected by developmental environments; and by raising questions about the evolutionary functions of feelings such as pleasure and suffering. To illustrate, stereotypic behavior (Box 1) can help to reveal plasticity in brain development and to identify attributes of natural environments necessary for this to progress normally. This varies between species, but for reasons that have barely been explored since the 1970s $[57,58]$.

Through their form and timing, stereotypic behaviors can also help to identify specific natural responses that are predisposed to persist even without apparent proximate benefits. This could reflect underlying control mechanisms that do not require reinforcing feedback from the environment. This type of control is predicted to evolve when learning would be challenging, for instance when the 


\section{Box 4. Sourcing data from animals in zoos and aquaria}

Visiting zoos to collect data

Pros: Can be productive, especially for taxonomically specialized collections such as bird gardens [31,54]; provides control over data quality and the precise variables recorded.

Cons: Assessment of multiple replicates (since individuals within one enclosure are non-independent) is potentially timetravel- and labor-intensive; data collection, especially for physiological variables, might require permission and/or assistance from zoo personnel.

\section{Collating data from publications}

Pros: As for any data mining research (see data sources below), including good statistical power at a low cost.

Cons: Welfare-oriented studies are skewed towards homeotherms, especially individuals and species with apparent problems. Thus, species that thrive in captivity are under-represented, and the true prevalence of welfare problems in a species cannot be estimated, just the severity of problems in affected subjects [22,32].

Using infant mortality data published annually for 1966-1998 in the International Zoo Yearbook, Vols 6-36

Pros: Freely available data on births or hatchings and deaths before 30 days; reported for many thousands of vertebrate species from zoos worldwide plus some US Regional Primate Research Centers.

Cons: Data are submitted voluntarily without quality checks (thus they suggest increasing infant carnivore mortality since the 1960s, probably reflecting better reporting [50]). Individual dam identities and non-independent animals sharing enclosures cannot be distinguished. 'Zoo' (rather than 'report' or 'year') is thus the most appropriate unit of statistical replication [22,32].

Using the US National Oceanic and Atmospheric Administration Marine Mammal Inventory Report (MMIR)

Pros: Data are publically available on acquisitions, births and deaths for thousands of individual pinnipeds and cetaceans captive since

benefits of an action accrue only after a delay [59] or when learning would have low value (e.g. natural environments are extremely unstable within a lifetime, or extremely predictable within and between generations [60,61]), predictions as yet little tested with data [61]. Potential mechanisms for such effects might include the activity involved instead being intrinsically self-rewarding or having the property that its prevention causes stress [2,62-64].

Behaviors with the latter property have been termed 'needs' by welfare researchers, who have been struck by the way that some natural activities seem to be crucial for wellbeing, even when captivity renders them functionally redundant $[2,64]$. One untested evo-mecho explanation [64] is that the benefits of these behaviors naturally vary more than their costs, making it adaptive for them to be driven by negative feelings reflecting homeostatic deficits or similar states of deprivation. It has been suggested that other natural behaviors, in contrast, are pleasure-driven when, evolutionarily, their costs vary more than their benefits, making rapid reactions to low-cost opportunities highly adaptive [64]. These are just some of the evo-mecho hypotheses inspired by the remarkable ways in which animals adjust to captivity, or fail to.

\section{Conclusions and future directions}

Poor captive welfare has ethical implications for those concerned about animal wellbeing and practical implications for those wishing to establish self-sustaining captive
1972; data are generally of good quality [http://dukespace.lib.duke. edu/dspace/handle/10161/230]; can be used for survivorship analyses. Cons: Stillbirths and neonatal deaths are sometimes under-reported [http://dukespace.lib.duke.edu/dspace/handle/10161/230]; walruses are excluded (the one pinniped species not covered).

Using data from studbooks (demographic records of genetically managed populations in zoos)

Pros: Largely good-quality data that include capture or birth dates, and dates and causes of death for individuals; in the public domain, although requests must be made on a case-by-case basis to the respective studbook keepers.

Cons: Studbooks are only in place for a subset of captive species ( 1200 [92]); thus, they were available for under half the carnivores used in one study [22,32] and just $25 \%$ of the cervids in another [33]. Quality can also vary and checking for internal errors is advisable $[19,20]$.

Using ARKS data from the International Species Inventory System (www.isis.org/)

Pros: ARKS provides studbook- or MMIR-quality data on births or hatchings and deaths for numerous species (nearly 10 000); related databases (e.g. MEDARKS) also contain physiological, morphometric, hematological and veterinary data.

Cons: Not in the public domain and so requires collaboration with participating zoos.

Using data from the Zoological Information Management System (http://www.isis.org/Pages/zims.aspx), the new system from ISIS Pros: As for ARKS and MEDARKS, but contains integrated physiological, morphometric, hematological, and veterinary data for zoo individuals; in the future will also provide husbandry and behavioral data.

Cons: As for ARKS and MEDARKS; ZIMS is also still in the process of being widely adopted or implemented (see the text) so that husbandry and behavioral data will not be available in quantity for several years.

populations. Species variation in welfare also has scientific implications for those needing captivity to generate valid, comparable data on, say, normal immune function or intrinsic optimum lifespan. Yet this variation between species also holds the key to solving some of these problems, as we have seen, with comparative methods being especially valuable for generating predictive frameworks about welfare and for testing hypotheses that could be tackled only with difficulty using more traditional approaches. Understanding species differences in captive welfare could also be biologically revealing, potentially providing insights into the adaptive value of different behavioral control mechanisms.

Furthermore, the enormous potential of applying comparative techniques to welfare issues has only just started to be explored. Table 1 provides many examples of still unexplained species variation in captive welfare; and many untested hypotheses, both old (Box 3) and new, also remain about factors conferring vulnerability or resilience. The vast amount of data collected in and by zoos is thus massively underused. For those wishing to now exploit this opportunity, Box 4 provides a guide to sources, from the ever-increasing number of welfare studies through to the data that zoos collate themselves. This last source is currently undergoing a revolution, with the impending arrival of ZIMS, the Zoological Information Management System (Box 4). ZIMS will integrate data on births or hatchings, deaths, and physiological, 
morphometric, hematological and veterinary variables (integrated historical data on 2.6 million individuals across 10000 species will be available to ISIS members in 2011). By 2013, all 800 member zoos should also be recording variables never collated before, such as simple aspects of behavior (e.g. whether or not stereotypic) and husbandry (e.g. enclosure size and complexity). Overall, greater exchange between animal welfare science and evolutionary ecology is thus not only mutually beneficial, but also timely and feasible.

\section{Acknowledgments}

I am grateful to an anonymous referee, Melissa Bateson, Dan Blumstein, Nuria Chapinal, Jamie Dallaire, Janet Higginson, Megan Jones, Heather Kinkaid, Jeanette Kroshko, Rob McLaughlin, Becky Meagher, Natalie Newby, Andy Sih and Cindy Todd for discussion and suggestions during the writing of this manuscript; to Hassan Syed, ISIS Chief Information Officer, for information on ZIMS; and to NSERC for funding.

\section{Appendix A. Supplementary data}

Supplementary data associated with this article can be found, in the online version, at doi:10.1016/j.tree. 2010.08.011.

\section{References}

1 McNamara, J.M. and Houston, A.I. (2009) Integrating function and mechanism. Trends Ecol. Evol. 24, 670-675

2 Dawkins, M.S. (2006) A user's guide to animal welfare science. Trends Ecol. Evol. 21, 77-82

3 Fraser, D. (2008) Understanding Animal Welfare: The Science in its Cultural Context, Wiley-Blackwell

4 Mason, G.J. and Veasey, J. (2010) How should the psychological welfare of zoo elephants be objectively investigated? Zoo Biol. 29, 237-255

5 Morgan, K.N. and Tromberg, C.T. (2007) Sources of stress in captivity. Appl. Anim. Behav. Sci. 102, 262-302

6 Romero, L.M. (2004) Physiological stress in ecology: lessons from biomedical research. Trends Ecol. Evol. 19, 249-256

7 Lind, J. and Cresswell, W. (2005) Determining the fitness consequences of anti-predation behaviour. Behav. Ecol. 16, 945-956

8 Wingfield, J.C. and Sapolsky, R.M. (2003) Reproduction and resistance to stress: when and how. J. Neuroendocrinol. 15, 711-724

9 Stankowich, T. and Blumstein, D.T. (2005) Fear in animals: a metaanalysis and review of risk assessment. Proc. R. Soc. B., Biol. Sci. 272, $2627-2634$

10 Réale, D. et al. (2007) Integrating animal temperament within ecology and evolution. Biol. Rev. Camb. Philos. Soc. 82, 291-318

11 Patton, M.L. et al. (2007) Review of contraception in ungulate species. Zoo Biol. 26, 311-326

12 Loudon, A.S. (1985) Lactation and neonatal survival of animals. Symp. Zool. Soc. Lond. 54, 183-207

13 Müller, D.W.H. et al. (2010) Comparing life expectancy of three deer species between captive and wild populations. Eur. J. Wildl. Res. 56, 205-208

14 Mason, G.J. and Veasey, J. (2010) What do population-level welfare indices suggest about the well-being of zoo elephants? Zoo Biol. 29, 256-273

15 Barnes, R. et al. (2002) Management and husbandry of duikers at the Los Angeles zoo. Zoo Biol. 21, 107-121

16 Willette, M.M. et al. (2002) Veterinary concerns of captive duikers. Zoo Biol. 21, 197-207

17 Clauss, M. et al. (2007) Tooth wear in captive giraffes (Giraffa cameleopardalis): mesowear analysis classifies free-ranging specimens as browsers but captive ones as grazers. J. Zoo Wildl. Med. 38, 433-445

18 Bashaw, M.J. et al. (2001) A survey assessment of variables related to stereotypy in captive giraffe and okapi. Appl. Anim. Behav. Sci. 73 , 235-247

19 Clubb, R. et al. (2008) Compromised survivorship in zoo elephants. Science 322, 1649
20 Clubb, R. et al. (2009) Fecundity and population viability in female zoo elephants: problems and possible solutions. Anim. Welf. 18, 237247

21 Bauman, K. et al. (2010) Global cheetah ex situ planning: Linking Managed Populations Working Group. Conserv. Breed. Specialist Group News 21, 1-4

22 Clubb, R. and Mason, G. (2007) Natural behavioural biology as a risk factor in carnivore welfare: how understanding species differences could help zoos redesign enclosures. Appl. Anim. Behav. Sci. 102, 303-328

23 Munson, L. et al. (2005) Extrinsic factors significantly affect patterns of disease in free-ranging and captive cheetah (Acinonyx jubatus) populations. J. Wildl. Dis. 41, 542-548

24 Blay, N. and Côté, I.M. (2001) Optimal conditions for breeding of captive Humboldt penguins (Spheniscus humboldti): a survey of British zoos. Zoo Biol. 20, 545-555

25 Ellenberg, U. et al. (2006) Physiological and reproductive consequences of human disturbance on Humboldt penguins: the need for speciesspecific visitor management. Biol. Conserv. 133, 95-106

26 Bunting, E.M. et al. (2009) Evaluation of oral itraconazole administration in captive Humboldt penguins (Spheniscus humboldti). J. Zoo Wildl. Med. 40, 508-518

27 Felsenstein, J. (2008) Comparative methods with sampling error and within-species variation: contrasts revisited and revised. Am. Nat. 171, 713-725

28 Blumstein, D.T. and Fernández-Juricic, E. (2010) A Primer of Conservation Behavior, Sinauer Associates

29 Fisher, D.O. and Owens, I. (2004) The comparative method in conservation biology. Trends Ecol. Evol. 19, 391-398

30 Chamove, A.S. et al. (1988) Visitors excite primates in zoos. Zoo Biol. 7, 359-369

31 Mettke, C. (1995) Ecology and environmental enrichment - the example of parrots. In Research and Captive Propagation (Gansloßer, U. et al., eds), pp. 257-262, Filander Verlag

32 Clubb, R. and Mason, G. (2003) Captivity effects on wide-ranging carnivores. Nature 425, 473-474

33 Müller, D.W.H. et al. (2010) Relevance of management and feeding regimens on life expectancy in captive deer. Am. J. Vet. Res. 71, 275280

34 Jeschke, J.M. and Strayer, D.L. (2006) Determinants of vertebrate invasion success in Europe and North America. Global Change Biol. 12, 1608-1619

35 Driscoll, C.A. et al. (2009) From wild animals to domestic pets, an evolutionary view of domestication. Proc. Natl. Acad. Sci. U. S. A. 106 (Suppl. 1), 9971-9978

36 Blumstein, D.T. (2006) Developing an evolutionary ecology of fear: how life history and natural history traits affect disturbance tolerance in birds. Anim. Behav. 71, 389-399

37 Holmes, N.D. et al. (2006) Behaviour and breeding success of Gentoo penguins Pygoscelis papua in areas of low and high human activity. Polar Biol. 29, 399-412

38 Walker, B.G. et al. (2006) Habituation of adult Magellanic penguins to human visitation as expressed through behaviour and corticosterone secretion. Conserv. Biol. 20, 146-154

39 Ellenberg, U. et al. (2007) Elevated hormonal stress response and reduced reproductive output in yellow-eyed penguins exposed to unregulated tourism. Gen. Comp. Endocrinol. 152, 54-63

40 Møller, A.P. (2008) Flight distance and population trends in European breeding birds. Behav. Ecol. 19, 1095-1102

41 Møller, A.P. (2009) Successful city dwellers: a comparative study of the ecological characteristics of urban birds in the Western Palearctic. Oecologia 159, 849-858

42 Hediger, H. (1950) Wild Animals in Captivity, Butterworths

43 McDougall, P.T. et al. (2006) Wildlife conservation and animal temperament: causes and consequences of evolutionary change for captive, reintroduced, and wild populations. Anim. Conserv. 9, 3948

44 Cassey, P. et al. (2004) Influences on the transport and establishment of exotic bird species: an analysis of the parrots (Psittaciformes) of the world. Global Change Biol. 10, 417-426

45 Landys, M.M. et al. (2004) Plasma corticosterone increases during migratory restlessness in the captive white-crowned sparrow Zonotrichia leucophrys gambelli. Horm. Behav. 46, 574-581 
46 Sol, D. et al. (2005) Big brains, enhanced cognition and response of birds to novel environment. Proc. Natl. Acad. Sci. U. S. A. 105, 54605465

47 Ruesink, J.L. (2005) Global analysis of factors affecting the outcome of freshwater fish introductions. Conserv. Biol. 19, 1883-1893

48 Sol, D. et al. (2008) Brain size predicts the success of mammal species introduced into novel environments. Am. Nat. 172, S63-S71

49 Magin, C.D. et al. (1993) Species extinctions, endangerment and captive breeding. In Creative Conservation: Interactive Management of Wild and Captive Animals (Olney, P.J.S. et al., eds), pp. 3-31, Springer

50 Ginsberg, J.R. and Macdonald, D.W. (1990) Foxes, Wolves, Jackals and Dogs - An Action Plan for the Conservation of Canids, IUCN

51 Derrickson, S.R. and Snyder, N.F.R. (1992) Potential and limits of captive breeding in parrot conservation. In New World Parrots in Crisis (Beissinger, S.R. and Snyder, N.F.R., eds), pp. 133-163, Smithsonian

52 Nunn, C.L. et al. (2003) A comparative study of white blood cell counts and disease risk in carnivores. Proc. R. Soc. Lond. B., Biol. Sci. 270, $347-356$

53 Martin, L.B. et al. (2007) Immune defense and reproductive pace of life in Peromyscus mice. Ecology 88, 2516-2528

54 Mettke-Hofmann, C. et al. (2005) Exploration of environmental changes relates to lifestyle. Behav. Ecol. 16, 247-254

55 Ricklefs, R.E. (2008) The evolution of senescence from a comparative perspective. Funct. Ecol. 22, 379-392

56 Shattuck, M.R. and Williams, S.A. (2010) Arboreality has allowed for the evolution of increased longevity in mammals. Proc. Nat. Acad. Sci. U. S. A. 107, 4635-4639

57 Einon, D.F. et al. (1981) Isolation has permanent effects upon the behavior of the rat, but not the mouse, gerbil or guinea pig. Dev. Psychobiol. 14, 343-355

58 Sackett, G.P. et al. (1976) Social isolation rearing: species differences in behavior of macaque monkeys. Dev. Psychol. 12, 283-288

59 Stephens, D.W. (1991) Change, regularity and value in the evolution of animal learning. Behav. Ecol. 2, 177-189

60 Dunlap, A.S. and Stephens, D.W. (2009) Components of change in the evolution of learning and unlearned preference. Proc. R. Soc. B., Biol. Sci. 276, 3201-3208

61 Mooring, M.S. et al. (2004) The evolution of parasite-defence grooming in ungulates. Biol. J. Linn. Soc. 81, 17-37

62 Mason, G. (2006) Stereotypic behaviour: fundamentals and applications to animal welfare and beyond, In Stereotypic Behaviour in Captive Animals: Fundamentals and Applications to Welfare (2nd edn) (Mason, G. and Rushen, J., eds), pp. 325-356, CAB International

63 Kirkwood, J. (2010) Darwinian selection, selective breeding and the welfare of animals. Anim. Welf. 19 (Suppl. 1), 1-5

64 Fraser, D. and Duncan, I.J.H. (1998) Pleasures", "pains" and animal welfare: toward a natural history of affect. Anim. Welf. 7, 383-396

65 Petter, J.J. (1975) Breeding of Malagasy lemurs in captivity. In Breeding Endangered Species in Captivity (Martin, R.D., ed.), pp. 187-202, Academic Press

66 Lindberg, D.G. et al. (1984) Primate breeding in zoos: a ten year summary. In One Medicine: A Tribute to Kurt Benirschke (Ryder, O.A. and Byrd, M.L., eds), pp. 162-170, Springer-Verlag

67 Tarou, L.R. et al. (2005) Survey of stereotypic behavior in prosimians. Am. J. Primatol. 65, 181-196

68 Jolly, A. et al. (2006) Territory as bet-hedging: Lemur catta in a rich forest and an erratic climate. In Ringtailed Lemur Biology: Lemur catta in Madagascar (Jolly, A. et al., eds), pp. 187-207, Springer

69 Small, R.J. and DeMaster, D.P. (1995) Survival of five species of captive marine mammals. Mar. Mamm. Sci. 11, 209-226
70 Woodley, T.H. et al. (1997) A comparison of survival rates for freeranging bottlenose dolphins (Tursiops truncatus), killer whales (Orcinus orca), and beluga whales (Delphinapterus leucas), Technical Report No. 97-02, International Marine Mammal Association

71 Couquiaud, L. (2005) Whales, dolphins and porpoises: presentation of the cetaceans. Aquat. Mamm. 31, 288-310

72 Reeves, R.R. et al. (2003) 2002-2010 Conservation Action Plan for the World's Cetaceans, IUCN

73 Connor, R.C. et al. (2000) The bottle-nose dolphin: social relationships in a fission-fusion society. In Cetacean Societies: Field Studies of Dolphins and Whales (Mann, J. et al., eds), pp. 91-126, University of Chicago Press

74 Dittrich, L. (1987) Observations on keeping the Pacific walrus Odobenus rosmarus divergens at Hanover Zoo. Int. Zoo Ybk. 26, 163-170

75 Gruber, A.D. et al. (2002) Atherosclerosis with multifocal myocardial infarction in a Pacific walrus (Odobenus rosmarus divergens). J. Zoo Wildl. Med. 33, 139-144

76 Cornell, L.H. and Asper, E.D. (1978) A census of captive marine mammals in North America. Int. Zoo Ybk. 18, 220-224

77 Kastelein, R.A. et al. (2003) Food consumption, growth and food passage times in Pacific walrus. Int. Zoo Ybk. 38, 192-203

78 Steenkamp, S. (2003) Oral biology and disorders of tusked mammals. Vet. Clin. North Am. Exot. Anim. Pract. 6, 689-725

79 van Zeeland, Y.R.A. et al. (2009) Feather damaging behaviour in parrots: a review with consideration of comparative aspects. Appl. Anim. Behav. Sci. 121, 75-95

80 Seibert, L.M. (2006) Feather-picking disorder in pet birds. In Manual of Parrot Behavior (Luescher, A.U., ed.), pp. 255-265, Blackwell

81 Clubb, S.L. (1992) The role of private aviculture in the conservation of neotropical psittacines. In New World Parrots in Crisis (Beissinger, S.R. and Snyder, N.F.R., eds), pp. 117-131, Smithsonian

82 Juniper, T. and Parr, M. (1998) Parrots: A Guide to Parrots of the World, Yale University Press

83 Garner, M.M. et al. (2008) Feather-picking psittacines: histopathology and species trends. Vet. Pathol. 45, 401-408

84 Kenward, R.E. (1974) Mortality and the fate of trained birds of prey. $J$. Wildl. Manage. 38, 751-756

85 Roberts, P.R. and Demaster, D.P. (2001) Pinniped survival in captivity: annual survival rates of six species. Mar. Mamm. Sci. 17, 381-387

86 Korte, S.M. et al. (2005) The Darwinian concept of stress: benefits of allostasis and costs of allostatic load and the trade-offs in health and disease. Neurosci. Biobehav. Rev. 29, 3-38

87 Glickman, S.E. and Hartz, K.E. (1964) Exploratory behavior in several species of rodents. J. Comp. Physiol. Psychol. 58, 101-104

88 Rosenthal, K.L. et al. (2004) Cytologic, histologic, and microbiologic characterization of the feather pulp and follicles of feather-picking psittacine birds: a preliminary study. J. Avian Med. Surg. 18, 137143

89 Clubb, R. and Vickery, S. (2006) Locomotory stereotypies in carnivores: does pacing stem from hunting, ranging or frustrated escape? In Stereotypic Behaviour in Captive Animals: Fundamentals and Applications to Welfare (2nd edn) (Mason, G. and Rushen, J., eds), pp. 58-85, CAB International

90 Mason, G. and Mendl, M. (1997) Do the stereotypies of pigs, mink and chickens reflect adaptive species differences in the control of foraging? Appl. Anim. Behav. Sci. 53, 45-58

91 Prescott, M.J. and Buchanan-Smith, H.M. (2004) Cage sizes for tamarins in the laboratory. Anim. Welf. 13, 151-158

92 Pelletier, F. et al. (2009) Value of captive populations for quantitative genetics research. Trends Ecol. Evol. 24, 263-270 